\section{P3.58 EARLY DIAGNOSIS OF HIV IN PREGNANT WOMEN: MONITORING AND ADOPTION OF PROFILATIC MEASURES TO REDUCE VERTICAL TRANSMISSION, RIBEIRÃO PRETO, 2007 TO 2015}

Elaine Cristina Manini Minto, Eduardo Bras Perin, Claudia Siqueira Vassimon, Renata Cristina Boscariol Manetta, Lis Aparecida Neves. Health Secretary of Municipal Government, Ribeirão Preto - SP, Brazil

\subsection{6/sextrans-2017-053264.293}

Introduction: As a consequence of the progressive increase in the number of AIDS cases in women in Brazil, Vertical Transmission (VT) has assumed great epidemiological importance. This way of transmission has become a major challenge for Public Health, demanding new surveillance strategies, mainly in order to guarantee HIV testing in prenatal care. Early diagnosis makes it possible to adopt prophylactic measures to avoid infection. The probability of transmission can reach $25.5 \%$ without any intervention, but preventive interventions can reduce to levels between $0 \%$ and $2 \%$. The objective of this study was to evaluate the efficacy of surveillance actions in the early diagnosis of HIV in pregnant women followed in Primary Care in Ribeirão Preto and the frequency of HIV infection in these pregnant women from 2007 to 2015.

Methods In Ribeirão Preto the HIV test is offered to all women as soon as the pregnancy is confirmed in the first care with the nurse; and it is repeated in the second and third trimesters of gestation. The Public Laboratory performs HIV testing on all pregnant women followed in Primary Care according to the Guidelines of the Technical Manual for the Diagnosis of HIV Infection established by Health Ministry. The Lab reports to the STD/AIDS Program for all REAGENT tests by email. The Program contacts the Health Unit where the pregnant is being followed. Afterwards they are referred to a specialised Health Unit in which they are monitored so that all the prophylactic measures are taken in time to avoid VT. The results were analysed through a retrospective study, using data from Information System for Notifiable Diseases (SINAN), Information System for Live Births (SINASC) and Information System of the Public Laboratory. All pregnant women attended between 2007 and 2015 were selected.

Results During the study period, 69827 children from mothers residing in Ribeirão Preto were born; 43856 (62.8\%) pregnant women were followed in Prenatal Care in a Public Health Unit and tested for HIV in the Public Laboratory. Among them, 103 (0.23\%) women were infected with HIV. In the same period, 265 HIV Positive pregnant women were notified on SINAN. The pregnant women who are already known to be HIV positive are directly referred to a specialised Public Health Unit. Five children under four years old HIV Positive were notified on SINAN: one child was born in another municipality, another child was born in the Private Health System and for the other three children, the mothers didn't look for prenatal care early in pregnancy.

Conclusion Early diagnosis, surveillance actions and monitoring of pregnant women in prenatal care in the Public Health System are effective in reducing VT. There is a direct communication between all the areas involved; an immediate exchange of information between the laboratory that performs the diagnosis and the assistance in the prenatal care. However, the major challenges are to seek and insert all pregnant women for early prenatal care in order to promote the monitoring of those who are HIV positive.

\section{P3.59 EVALUATING 90-90-90 TREATMENT TARGET IN A PUBLIC CLINIC AT SÃO PAULO METROPOLITAN AREA}

'EM Matsuda, ${ }^{2}$ Opromolla PA, ${ }^{3}$ LPO Coelho, GF Romero ${ }^{3},{ }^{3}$ LFM Brígido. ${ }^{1}$ Santo André AIDS Program, Santo André, Brazil; ${ }^{2}$ Coordination of Science, Technology and Strategic Health (CCTIES), São Paulo, Brazil; ${ }^{3}$ Virology Centre, Adolfo Lutz Institute, São Paulo, Brazil

\subsection{6/sextrans-2017-053264.294}

Introduction: Controlling the epidemic by increasing access to care and suppressing viremia with adequate treatment is a central instrument in the UNAIDS and Brazilian strategy plan. Monitoring the implementation of test and treatment program is important to adjust the strategy to the different real world scenarios.

Methods We evaluated the outcome of 239 patients newly diagnosed HIV infections consecutively recruited from January 2011 to February 2015. Response to antiretroviral therapy (ART), CD4 (BD, USA) and viral load (Abbott, USA) were evaluated prospectively. Continuous variables as median and 25th-75th percentiles (IQR).

Results Most patients were (194/239 81.2\%) male, 134/194 (69\%) men who have sex with men, 109/204 (46\%) white, age 32 (25-41), with disease staging (CDC2014) Zero (6.3\%), 1 (33.1\%), 2 (31.4\%) e 3 (29.3\%), with CD4 388 cells $/ \mathrm{mm}^{3}$ (205-616) and viral $\operatorname{load} \log _{10} 4.55$ (3.99-5.12). Follow-up information was available to $200 / 239$ (83.7\%), with 39 lost to follow-up due to: transferred without information 10 (4.18\%), abandoned $20(8.4 \%)$ and death 9 (3.8\%). Treatment was prescribed to $212 / 239(88.7 \%)$, with 6 deaths before initiating ART, 21 refusing treatment or loss to follow-up. Among 212 treated, at week $24,171 / 212(80.7 \%)$ had viral $\operatorname{load} \log _{10}<3$ $(<1000$ copies/mL, WHO suppression target) and $79 \%<200 \mathrm{c}$ $1 \mathrm{~mL}$ (DHHS suppression target). If only cases with information were considered $(n=190), 90 \%$ and $89 \%$ (WHO/DHHS criteria, respectively). In the last observation, after a median follow-up of 127 weeks (91-178), viral suppression was $83.7 \%$ and $80.3 \%$ (WHO/DHHS) on all 239 cases and $92.5 \%$ and $89 \%$ among treated cases. Most (69\%) had a CD4 $>500$ cells $/ \mathrm{mm} 3,71.6 \%$ if only treated were considered.

Conclusion Newly diagnosed patient at public health service approach the viral suppression target, showing the feasibility of this goal. The high mortality after diagnostic, especially before treatment, warrants to the need to improve the identification and incorporation of this subgroup with advance disease.

\section{P3.60 FACTORS ASSOCIATED TO PROTECTED SEX IN YOUTHS}

${ }^{1}$ Eliana Gutierrez, ${ }^{1}$ Valdir Monteiro Pinto, Mariia Elisabethb. ${ }^{1} \mathrm{M}$ Lopes, ${ }^{2}$ Claudia Renata Santos Barros, ${ }^{3}$ Caritas Relva Basso. 1. Programa Municipal DST/AIDS, São Paulo SP - BRAZIL; ${ }^{2}$ Universidade Católica De Santos, Santos - SP - BRAZIL; ${ }^{3}$ Programa Municipal DST/AIDS, Sao Paulo - SP - BRAZIL

\subsection{6/sextrans-2017-053264.295}

Introduction The study aimed to identify the factors associated with condom use during the last sexual intercourse.

Methods A population-based survey with youths aged 15-24, in São Paulo. The participants answered a questionnaire including knowledge and sexual behavioural data.

Results for 821 men and women the condom use during the last sexual intercourse was associated with: never having been married [adjusted prevalence ratio $\left(\mathrm{PR}_{\mathrm{adj}}\right)$ : 1.54 among men; 1.26 among women], having used a condom in the sexual 